\title{
Regulatory signals in messenger RNA: determinants of nutrient-gene interaction and metabolic compartmentation
}

\author{
John E. Hesketh*, M. Helena Vasconcelos $\dagger$ and Giovanna Bermano \\ Rowett Research Institute, Greenburn Road, Bucksburn, Aberdeen AB21 9SB, UK
}

(Received 10 November 1997 - Revised 27 April 1998 - Accepted 1 May 1998)

\begin{abstract}
Nutrition has marked influences on gene expression and an understanding of the interaction between nutrients and gene expression is important in order to provide a basis for determining the nutritional requirements on an individual basis. The effects of nutrition can be exerted at many stages between transcription of the genetic sequence and production of a functional protein. This review focuses on the role of post-transcriptional control, particularly mRNA stability, translation and localization, in the interactions of nutrients with gene expression. The effects of both macronutrients and micronutrients on regulation of gene expression by post-transcriptional mechanisms are presented and the post-transcriptional regulation of specific genes of nutritional relevance (glucose transporters, transferrin, selenoenzymes, metallothionein, lipoproteins) is described in detail. The function of the regulatory signals in the untranslated regions of the mRNA is highlighted in relation to control of mRNA stability, translation and localization and the importance of these mRNA regions to regulation by nutrients is illustrated by reference to specific examples. The localization of mRNA by signals in the untranslated regions and its function in the spatial organization of protein synthesis is described; the potential of such mechanisms to play a key part in nutrient channelling and metabolic compartmentation is discussed. It is concluded that nutrients can influence gene expression through control of the regulatory signals in these untranslated regions and that the post-transcriptional regulation of gene expression by these mechanisms may influence nutritional requirements. It is emphasized that in studies of nutritional control of gene expression it is important not to focus only on regulation through gene promoters but also to consider the possibility of post-transcriptional control.
\end{abstract}

Gene expression: Untranslated regions: Post-transcriptional regulation

\section{Nutrition and gene expression}

Although nutritional science has defined many of the necessary constituents of an adequate diet in terms of both macro- and micronutrients, the feeding of such a diet to two different individuals or to the same individual under different circumstances can give rise to different metabolic or even clinical effects. For example, on the same energy intake one individual becomes obese but another does not; equally, different individuals have varying requirements for micronutrients to maintain health. A major challenge to modern nutrition is to understand the basis for such differences in nutrient requirements and to relate this to the achievement of optimal health and performance. This requires an appreciation not only of the traditional links between nutrition and endocrine status but also of the less well-defined links between nutrition and gene expression. With the on-going expansion in molecular biology and genetics we are now beginning to be able to address the latter aspects. An ability to define the interactions between nutrition and gene expression will enable nutritionists to identify individuals with particular dietary needs.

In a broad sense this entails understanding how the role of nutrients in health and metabolism is linked to biochemical events which lead to gene expression. As shown schematically in Fig. 1, this can be reduced to two inter-linked

\footnotetext{
Abbreviations: apo, apolipoprotein; cGSH-Px, cytosolic glutathione peroxidase; GLUT, glucose transporter; G6PDH, glucose-6-phosphate dehydrogenase; GRP78, glucose-regulated protein 78; IDI, iodothyronine $5^{\prime}$ deiodinase; IRE, iron-regulatory elements; IRP, iron-regulatory proteins; MT, metallothionein; PHGSH-Px, phospholipid hydroperoxide glutathione peroxidase; poly(A), polyadenylate; UTR, untranslated regions.

*Corresponding author: Dr John Hesketh, fax +44 (0) 1224 716622, email J.Hesketh@ @ri.sari.ac.uk

$\dagger$ Present address: Instituto de Patologia e Imunologia Molecular da Universidade do Porto IPATIMUP, Rua Roberto Frias s/n, 4200 Porto, Portugal.
} 


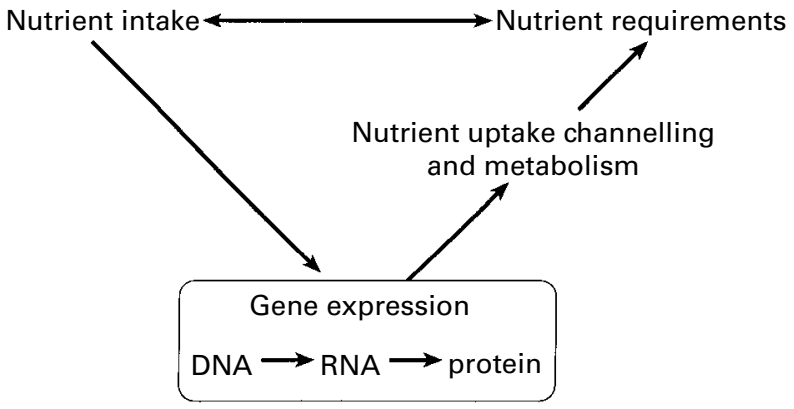

Fig. 1. Inter-relationships of nutrition and gene expression.

processes: the influence of nutrient intake on gene expression and protein synthesis, and the influence of gene expression on nutrient requirements. In specific terms it involves addressing important fundamental questions: which genes, particularly those involved in the control of metabolism, growth and differentiation are regulated by nutrition; how do nutrients and diet regulate the expression of specific genes; and how is the expression of specific gene products involved in metabolism and channelling of nutrients?

The genetic information in the DNA is transcribed into an RNA copy of the gene (the primary transcript) which is processed to produce a mature mRNA molecule. The mRNA is then transported from the nucleus to the cytoplasm where it is translated to produce a protein according to the amino acid sequence encoded in the mRNA and the gene. Potentially, the expression of any gene can be regulated at different steps between its transcription and synthesis of the final active protein product. There is increasing evidence that in addition to regulation of transcription itself, many genes are regulated post-transcriptionally during the processing, transport and translation of the mRNA. It is important to emphasize that nutrition may alter the amount of functional protein expressed by a specific gene through a range of transcriptional, post-transcriptional and post-translational mechanisms. However, this review focuses on post-transcriptional regulation, illustrates its relevance to nutrition and develops an integrated picture of how post-transcriptional regulation is involved in the interaction between nutrition and gene expression. To achieve this we briefly describe the principal features of post-transcriptional regulation and then describe the increasing number of genes whose post-transcriptional regulation has been shown to be affected by nutrients. The mechanisms of regulation by specific nutrients and their role in controlling protein synthesis, protein distribution and nutrient channelling within cells are highlighted. The approach is selective rather than comprehensive, and our overall aim is to highlight the possibilities of nutrient control of gene expression through post-transcriptional mechanisms, without diminishing the roles of other regulatory events.

\section{The regulatory mechanisms and signals}

\section{Critical control points}

The amount of protein produced from any gene can be regulated at many points between conversion of the gene sequence to the mRNA to the protein. The activity of the gene itself in producing RNA transcripts is regulated by the promoter region to which specific transcription factors can bind. Transcription produces a copy of the whole gene sequence, including both the exons (regions which code for protein) and introns (sections of non-coding DNA). Following gene transcription to produce a primary RNA transcript, the RNA is converted to a mature mRNA within the nucleus; this involves splicing and polyadenylation where introns are removed and adenine residues (polyadenylate (poly(A)) tails) added at the $3^{\prime}$ end of the mRNA. During processing certain mRNA, apparently only a few, can be edited. The mRNA is then transported from the nucleus to the cytoplasm. Theoretically, there are three possible fates for fully processed mRNA in the cytoplasm: they may be actively translated to produce protein, they may be sequestered in an untranslated form, or they may be degraded. Translation can be controlled either by regulating the availability of the mRNA for translation or regulating the initiation or elongation steps of the translation process. Certain mRNA are localized at specific subcellular sites. Post-transcriptional regulation of gene expression refers to the modulation of these processes (Wolfe, 1993) to determine how much, where and when specific proteins are produced (see Fig. 2).

In eukaryotes all mRNA contain not only coding sequences, which are translated to produce the appropriate protein, but also untranslated sequences. These untranslated sequences are present at both the $5^{\prime}$ and $3^{\prime}$ ends of the coding region and are referred to as the $5^{\prime}$ and $3^{\prime}$ untranslated regions, 5'UTR and 3'UTR respectively. By using recombinant DNA techniques to produce modified genes in which $5^{\prime}$ and $3^{\prime}$ UTR are altered, exchanged or removed, in combination with transfection techniques to introduce the modified genes into cells in culture, it has been demonstrated that regulatory elements are present in the UTR from a number of mRNA. From such studies it has become evident that UTR have a central and critical role in controlling gene expression by regulating the polyadenylation, translation, stability and localization of mRNA. This regulation is achieved by the interaction of the UTR with specific proteins. There is relatively little information available on the precise nature of many of the $5^{\prime}$ and $3^{\prime}$ UTR signals, but in those cases where the regulatory elements have been closely mapped they have been found to consist of relatively short UTR sequences. The available data are compatible with some form of secondary RNA structure such as a bulge or a stem-loop being critical for regulation, and these structures in the RNA appear to exert their regulatory functions by binding specific proteins (Kozak, 1992; McCarthy \& Kollmus, 1995). 5'UTR tend to be relatively short in length and to date their functions have been found to be restricted to regulation of translation (Kozak, 1992). In contrast, 3'UTR can be up to hundreds or thousands of bases in length, can contain conserved regions and have been implicated in a wide range of regulatory events such as control of mRNA stability, translation, polyadenylation and localization. For example, the regulation of the synthesis of 3-hydroxy-3-methyglutaryl-CoA reductase (EC 1.1.1.88) is at the post-transcriptional level and studies with constructs in which its $3^{\prime}$ UTR is linked to $\beta$-globin show that 

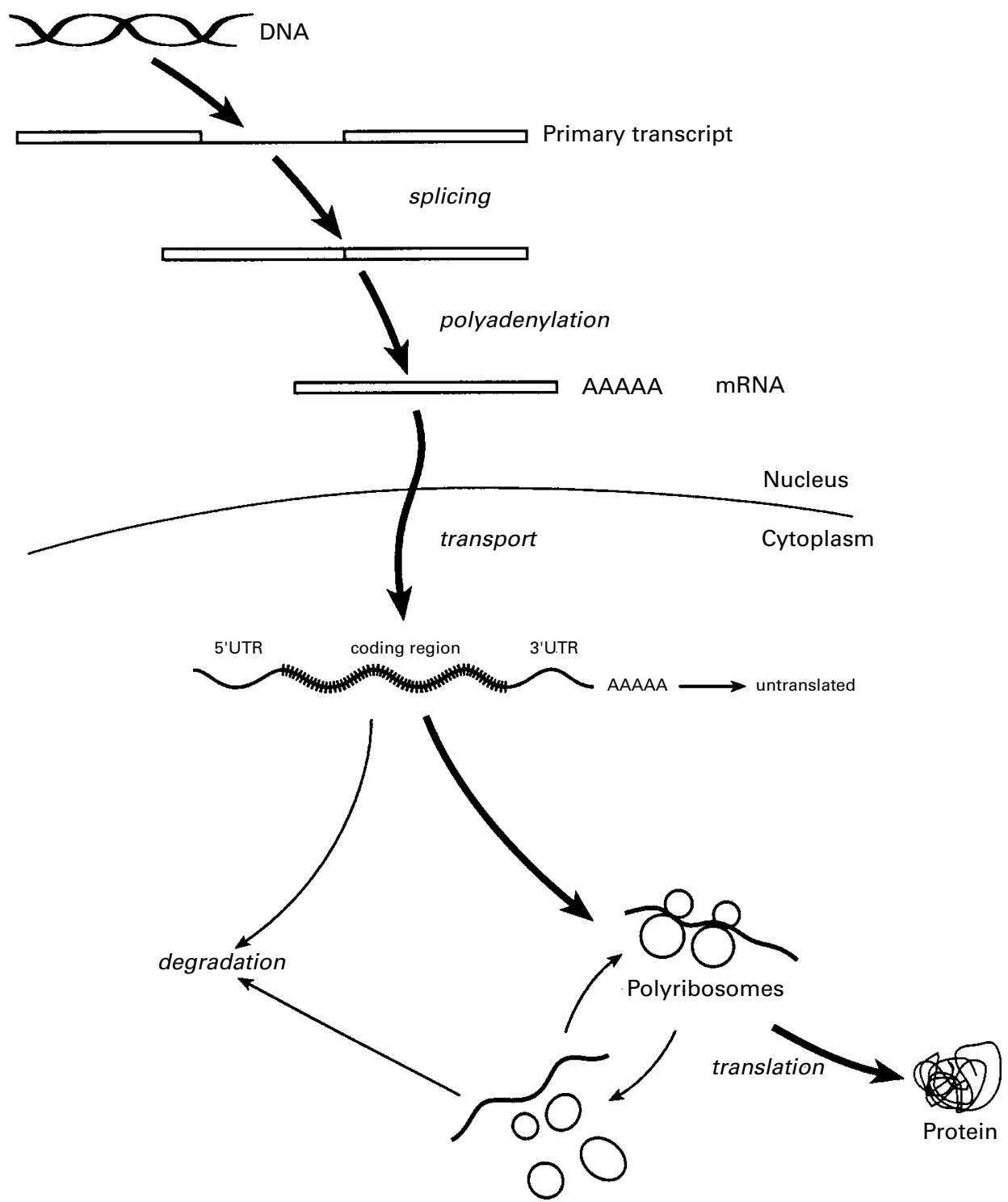

Fig. 2. Post-transcriptional control of gene expression. The diagram illustrates the critical stages and possible control points between transcription of the gene and synthesis of the corresponding protein. $5^{\prime} U T R, 5^{\prime}$ untranslated region; $3^{\prime} U T R, 3^{\prime}$ untranslated region.

regulation of synthesis by oxysterols depends on the $3^{\prime} \mathrm{UTR}$ (Choi \& Peffley, 1995). As illustrated in Fig. 3, the picture emerging of post-transcriptional control is that translation, localization and stability of an mRNA are determined by the interactions between RNA structures in the $5^{\prime}$ and $3^{\prime}$ UTR and proteins which bind to these structures.

\section{Regulation of nuclear mRNA processing}

A key step in RNA processing is the removal of intron sequences by splicing. In some cases this produces different mRNA from a single primary transcript, an event known as alternative splicing (Amara et al. 1982); this may generate mRNA with different coding sequences (and therefore producing subtly different proteins), inefficient or non-functional mRNA (Garrett et al. 1989) or UTR with different secondary structure and binding-sites for regulatory proteins (and therefore different responses to regulation). An example of the latter is the alternative splicing in the first three exons of the $\beta$-subunit of mouse thyrotropin gene which produces mRNA with different $5^{\prime}$ UTR and different translational efficiencies (Januszeski \& Gurr, 1991).

In a few cases the sequence of the primary transcript can be modified by a process called RNA editing. In mammals this event appears to be rare but it is more common in lower eukaryotes. Editing involves the binding of proteins or short RNA templates to specific regions of the primary transcript and subsequent alteration or 'editing' of the sequence, either insertion of one or more $\mathrm{U}$ nucleotides or base changes such as $\mathrm{C}$ to $\mathrm{U}$ or A to I (Scott, 1989). This mechanism allows production of different proteins from a single gene under different physiological conditions, as for example with apolipoprotein (apo) B (Baum et al. 1990).

Polyadenylation of mammalian mRNA at the $3^{\prime}$ end 


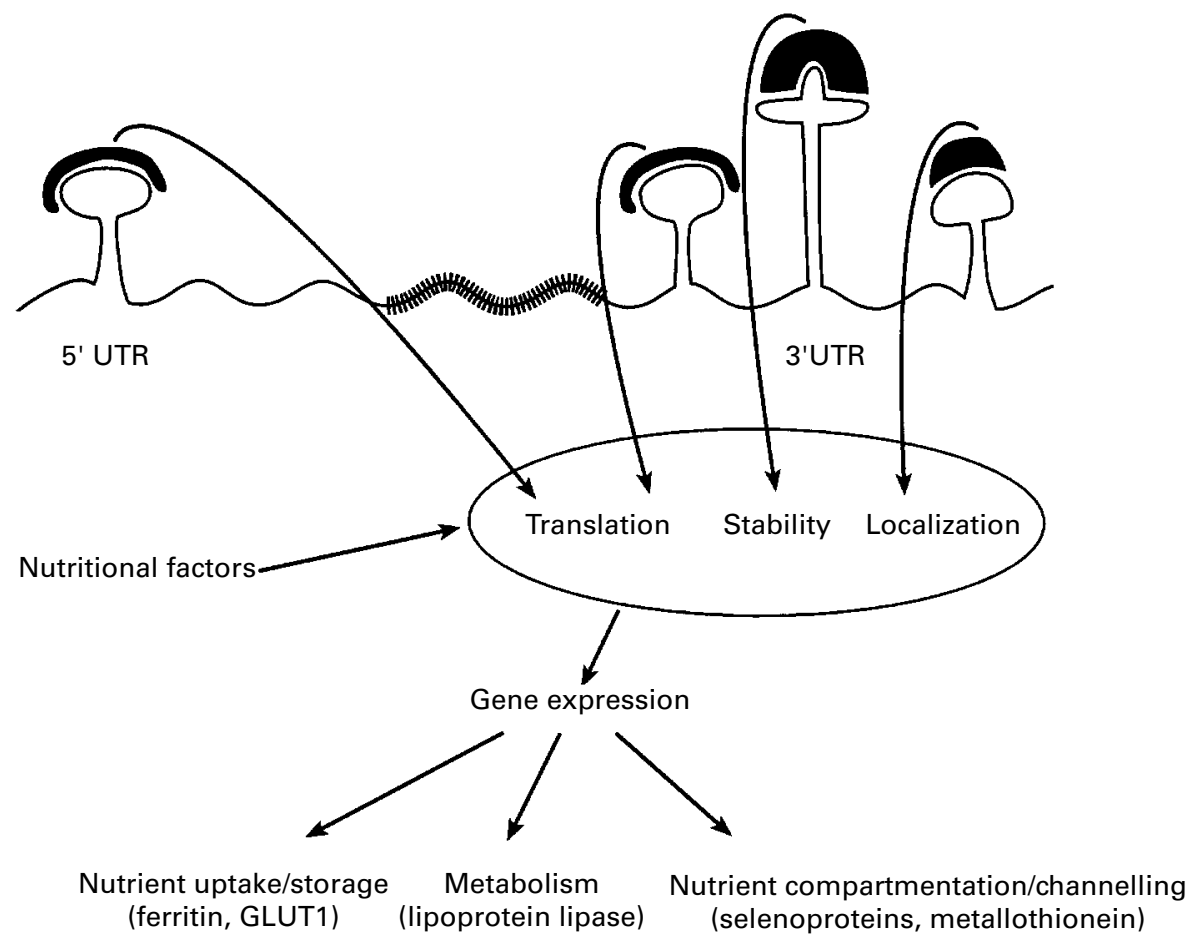

Fig. 3. Regulatory signals in the untranslated regions and their interactions with nutrition. The diagram illustrates schematically that untranslated regions (UTR) of mRNA contain regulatory signals which control the translation, stability and localization of mRNA, and thus gene expression. These regulatory signals in the mRNA bind specific proteins $(\boldsymbol{\square})$ and the protein-RNA interaction responds to nutritional factors to control the expression of gene products of nutritional significance, as shown schematically for certain specific examples. GLUT-1, glucose transporter-1.

occurs in the nucleus soon after transcription. Usually mRNA have 200-250 adenylate residues when transported into the cytoplasm and then these 'poly(A) tails' are usually shortened to 50-70 residues by cytoplasmic enzymes (Hershey, 1991). The polyadenylation status of many mRNA is important in determining the extent of both their translation and degradation (Jackson \& Standart, 1990) in the cytoplasm. Once an mRNA has been spliced and polyadenylated it is transported to the cytoplasm. The mechanism of this RNA export from the nucleus is poorly understood (Izarrulde \& Mattaj, 1995) but it is possible that regulation could also occur at this stage; indeed, recently it was suggested that synthesis of one of a family of cell-cycle regulators (cyclin D1) is regulated post-transcriptionally by the translation initiation factor eIF4E through its involvement in the transport of the cyclin D1 mRNA from the nucleus to the cytoplasm (Rosenwald et al. 1995).

\section{mRNA translation}

Regulation of the extent to which specific mRNA are translated is largely achieved by controlling the initiation of translation through formation of a complex between specific regulatory proteins, the mRNA and the small ribosomal subunit (Gray \& Hentze, 1994; Morley, 1994). Several factors have been identified as particularly important in determining the extent to which an mRNA is translated. First, the structure of the $5^{\prime} \mathrm{UTR}$, particularly specific stem-loops which bind proteins, is critical in determining whether an mRNA is translated or sequestered in an untranslated ribonucleoprotein complex (McCarthy \& Kollmus, 1995). Some of these proteins are cell-specific and mRNA-specific, allowing precise post-transcriptional control over the synthesis of specific proteins (Richter, 1991; Hentze, 1995; McCarthy \& Kollmus, 1995). Initiation of translation is dependent on the presence of the $5^{\prime}$ cap structure and the structure of the mRNA next to the initiation codon: indeed, secondary structures such as stem loops in the $5^{\prime}$ end of the mRNA seem to inhibit initiation of translation. Second, both the ability of the mRNA to compete for limited amounts of initiation factors and the phosphorylation of the elongation initiation factors eIF4E and eIF4G are important. Third, the poly(A) tails are also involved in the modulation of translation. Although they are not essential for translation to occur, mRNA lacking the poly(A) tail are less efficiently translated; for example, Xenopus $\beta$-globin mRNA without poly(A) tails formed smaller polyribosomes (Galili et al. 1988) indicating a lower translational efficiency. A protein which binds specifically to these poly(A) tails, the poly(A) binding protein, has a possible role in the formation of the translation initiation complex (Sachs \& Davis, 1990). Some proteins, for example dihydrofolate reductase (EC 1.5.1.3) and thymidylate synthase (EC 2.1.1.45), are capable of regulating the translation of their own mRNA; thymidylate synthase regulates translation by binding to a part of the mRNA that includes the AUG codon (Chu et al. 1993). 


\section{mRNA stability}

The amounts of some mRNA available for translation are regulated by controlling their stability and turnover, and thus their effective intracellular concentration. The regulation of mRNA stability is complex and can involve elements in both the coding and untranslated sequences, although in particular there is an increasing number of examples in which $3^{\prime}$ UTR sequences are involved in determining stability of mRNA. The proto-oncogene $c$-fos codes for a highly unstable mRNA which has a half-life of approximately $30 \mathrm{~min}$ and its instability is due to sequences in the $3^{\prime}$ UTR. Replacement of the endogenous $3^{\prime}$ UTR in fos mRNA by that from $\beta$-globin, which has a half-life of approximately $24 \mathrm{~h}$, produces a stable chimaeric transcript (Veyrune et al. 1995) whilst addition of the fos $3^{\prime}$ UTR to $\beta$ globin confers instability. Within $3^{\prime}$ UTR, certain AUUUA sequences, particularly multiple AUUUA sequences in close proximity or AU-rich regions, have been implicated in mRNA instability (Chen \& Shyu, 1995). In contrast, isolated AUUUA sequences may have other regulatory functions, for example in translation and mRNA localization (Veyrune et al. 1996). Polyadenylation status also influences mRNA degradation; for example, $c$-myc, $c$-fos and metallothionein (MT) mRNA, deadenylation and degradation may be linked; when the poly(A) tail of MT mRNA is shortened to 30-40 residues the mRNA levels decrease (Mercer \& Wake, 1985), indicating degradation. However, it is not known if poly(A) removal is a general mechanism of mRNA degradation (Surdej et al. 1994).

\section{mRNA localization}

Not only is the extent of translation of individual mRNA controlled but also the site of their translation in the cell. Secreted and membrane proteins are synthesized on the endoplasmic reticulum with the ribosome-mRNA complex being targeted there by a signal in the nascent polypeptide chain. In addition, it is now appreciated that there is a more complex spatial organization of the protein synthesis apparatus whereby mRNA for intracellular proteins are targeted to different parts of the cytoplasm (Hesketh, 1994, 1996a). Although mRNA localization was first observed in Drosophila embryos and Xenopus oocytes, it is now clear that the phenomenon occurs in somatic mammalian cells (Hesketh, 1996a); the perinuclear cytoplasm, peripheral cytoplasm, peri-mitochondrial cytoplasm and muscle costameres are amongst the various subcellular domains to which mRNA are directed. This targeting of mRNA coding for intracellular proteins is achieved by signals in the $3^{\prime}$ UTR and it also involves the cytoskeleton (Hesketh, 1996a). Under growth conditions when actin synthesis is required in the cell periphery the $3^{\prime}$ UTR from $\beta$-actin targets this transcript to the cell periphery (Kislauskis et al. 1993). In contrast, the $3^{\prime}$ UTR of the c-myc mRNA is essential for its perinuclear localization and association with the cytoskeleton (Hesketh et al. 1994), and it has been suggested that this localization ensures efficient import of the protein into the nucleus (Hovland et al. 1995; Veyrune et al. 1996). In both these examples the localization signal has been at least partially defined and it was found that relatively short (40-90 nucleotide) sequences from these UTR are sufficient to produce localization (Kislauskis et al. 1993; Hesketh, 1996a). In Drosophila, localization has been demonstrated to provide a mechanism for translational control in which both localization and repression of translation are controlled by $3^{\prime}$ UTR sequences (Gavis \& Lehmann, 1994). The relationship between localization and translation in mammalian cells is less clear but correct localization appears not to be obligatory for translation. In general, the function of mRNA localization is to provide local synthesis of protein and thus contribute to the efficient delivery and compartmentation of specific proteins.

\section{Nutrition and post-transcriptional control}

Both macronutrients (carbohydrates, fatty acids, proteins and/or amino acids) and micronutrients (trace metals, Se, vitamins) participate, in concert with endocrine factors, in the regulation of gene expression in response to nutritional changes (Clarke \& Abraham, 1992). There is increasing evidence that the response of gene expression to nutrients involves control of post-transcriptional events but it is often unclear whether the regulatory factors involved are the dietary components themselves, their metabolites or hormonal changes produced in response to the dietary changes.

Much of the evidence for post-transcriptional control comes from observed discrepancies between either mRNA abundance and transcription rates (altered mRNA abundance associated with unchanged gene transcription implies an altered mRNA stability) or in mRNA abundance and protein concentrations (altered protein concentration in the absence of any change in mRNA abundance implies either altered translation of the mRNA or changes in proteolytic breakdown of the protein). Many examples exist where alterations in nutritional status lead to such discrepancies. In the case of many mRNA-nutrient interactions, as for example in the post-transcriptional events playing a role in metabolic responses to dietary restriction and changes in macronutrient supply, this remains essentially the only evidence for post-transcriptional control. In some other cases, for example the glucose transporters and lipoprotein lipases, evidence for mechanisms and a role of the UTR is emerging whilst in a few instances, such as the incorporation of Se and the regulation of ferritin and transferrin receptor by intracellular $\mathrm{Fe}$, details of the role of the UTR and associated binding proteins have been elucidated.

\section{Starvation, macronutrients and energy restriction}

In rats starvation decreases both the amount and activity of glycogen synthase (EC 2.4.1.11) but glycogen synthase mRNA abundance does not differ significantly between fed, starved and refed rats (Nur et al. 1995). In addition less glycogen synthase mRNA is associated with polyribosomes in starved rats than in fed rats, suggesting some form of translational control. There is evidence that this regulation involves an mRNA-binding protein but it is not clear with which part of the mRNA it associates or how it regulates translation (Nur et al. 1995).

Whereas starvation has an inhibitory effect on lipogenesis, a high-carbohydrate diet generally has a stimulatory 
effect. Both dietary changes alter the activity of key lipogenic enzymes, in particular acetyl-CoA carboxylase $(E C$ 6.4.1.2) and fatty acid synthase (EC 2.3.1.85) (Clarke et al. 1990; Katsurada et al. 1990a). Feeding a high-carbohydrate diet increases the acetyl-CoA carboxylase mRNA concentration, the rate of transcription and enzyme activity but the increase in acetyl-CoA carboxylase mRNA level is greater than that accounted for by the increase in transcription rate, suggesting that the high-carbohydrate diet both stimulates transcription of the acetyl-CoA carboxylase gene and stabilizes the mRNA (Katsurada et al. 1990a). Similarly, the dietary regulation of hepatic fatty acid synthase mRNA levels has been reported to occur at both transcriptional and post-transcriptional levels (Katsurada et al. 1990b). The mechanism by which feeding a high-carbohydrate diet leads to enhanced expression of these mRNA has not been identified. However, it has been proposed that products of glucose metabolism, possibly glucose-6-phosphate, stimulate the production of lipogenic enzymes (Foufelle et al. 1992).

Similarly, nutritional control of hepatic glucose-6-phosphate dehydrogenase (EC 1.1.1.49; G6PDH) and malic enzyme ( $E C$ 1.1.1.40) activities involves regulation of mRNA stability. In rats fed on a high-carbohydrate diet after starvation, changes in G6PDH activity are accompanied by alterations in G6PDH mRNA abundance (Kletzien et al. 1985; Fritz et al. 1986) and measurement of rates of transcription and mRNA degradation (Prostko et al. 1989) indicated both a stimulation of transcription of the G6PDH gene and an increased stability of the mRNA. In the case of malic enzyme, mRNA levels are readily increased by dietary carbohydrate, but transcription rates, as determined in vitro using isolated nuclei (nuclear run-on assays) are unchanged; this suggests that changes in mRNA abundance are determined by mRNA stability and not gene transcription (Dozin et al. 1986).

Dietary energy restriction also affects the expression of various genes, in particular that encoding the glucoseregulated protein 78 (GRP78) (Tillman et al. 1996), a protein located in the endoplasmic reticulum which is essential for proper folding, assembly and glycosylation of proteins (Little et al. 1994). In mice fed on an energyrestricted diet, a reduction in GRP78 protein levels was observed to be closely paralleled by a reduction in hepatic GRP78 mRNA levels (Spindler et al. 1990), indicating that energy restriction does not influence the rate of translation or the stability of GRP78 protein. However, measurement of transcription rates in vitro using isolated nuclei failed to show any effect of energy restriction on the rate of transcription, suggesting that dietary restriction regulates synthesis of GRP78 protein by destabilization of its mRNA.

Restriction of dietary protein or amino acid intake reduces the rate of growth of young animals. There is some evidence that this is accompanied by post-transcriptional changes in the expression of certain growth-related genes such as c-myc (Yokota et al. 1995a). Furthermore, a similar effect has also been observed in vitro: in media deprived of amino acids cells show increased abundance of c-myc mRNA which is due to an approximately 6-fold increase in mRNA stability, as shown by the prolonged half-life (Yokota et al. 1995b). It was suggested that this was due to the suppression of the synthesis of a short-lived cytosolic protein which is involved in the degradation of the mRNA. The expression of genes associated with growth arrest has also been reported to be regulated in part by posttranscriptional mechanisms (Coccia et al. 1992; Fleming et al. 1998).

A protein-restricted diet also increases the transcription of the insulin-like growth factor binding protein-1 gene (Straus et al. 1993). However, because the observed increase in the primary transcripts was less than that of the mature insulin-like growth factor binding protein-1 mRNA, it is probable that there was also a stabilization of the mRNA when protein synthesis was reduced.

\section{Lipoproteins: RNA editing, stability and translation}

The two apolipoproteins apoB-100 and apoB-48 are both encoded by the same gene but apoB-48 is formed as a result of a post-transcriptional modification of the apoB-100 transcript (Scott, 1989; Baum et al. 1990) in which RNA editing converts the cytosine at position 2153 to uracil and so forms a premature stop codon (UAA). This editing produces two dramatically different proteins from the one gene, the apoB- 48 produced from the truncated transcript being of much smaller molecular mass $(34 \mathrm{kDa})$ than the apoB-100 produced from the full transcript; the larger apoB100 contains the LDL-receptor binding site. The degree of editing appears to differ between tissues: in the intestine apoB-48 is produced and incorporated into chylomicrons for absorption of dietary lipids; in man the liver produces only the larger apoB-100 form (an important component of VLDL and LDL complexes) but in the rat the liver synthesizes both apoB-48 and apoB-100 proteins. Although highsucrose diets have no effect on total hepatic apoB secretion (Strobl et al. 1989), the ratio apoB-100 : apoB-48 proteins is markedly altered (Baum et al. 1990). It has been suggested that the effect of carbohydrate feeding on apoB-100:apoB48 is due to regulation of the editing of the apoB RNA transcripts by dietary carbohydrate. Fasting has itself also been reported to reduce apoB RNA editing (Leighton et al. 1990). These data indicate that diet influences apoB-48 and/ or apoB-100 synthesis by modulation of mRNA processing, specifically mRNA editing.

Diets rich in lipid, particularly saturated fatty acids and cholesterol, also influence lipoprotein metabolism; they increase LDL and HDL particles in plasma (Goldberg \& Schonfeld, 1985; Sorci-Thomas et al. 1989; Srivastava et al. 1991) and increased levels of plasma LDL have been identified as a risk factor for CHD (Gofman et al. 1966). Thus, the influence of diet on lipoprotein metabolism is of major interest. Turnover of components of both LDL and HDL has been shown to involve post-transcriptional mechanisms. In vivo, oxidized LDL is taken up by scavenger receptors in macrophages. The expression of the scavenger receptor gene is inhibited by tumour necrosis factor- $\alpha$ and this regulation occurs through a decrease in mRNA stability (Hsu et al. 1996).

Since the synthesis and secretion of plasma lipoproteins are often correlated with the production of their corresponding apolipoproteins (Srivastava et al. 1992), the expression of 
apoAI, the major protein component of HDL, has received considerable attention. The synthesis and secretion of apoAI is regulated by transcriptional, post-transcriptional and posttranslational control mechanisms. In rats fed on diets of high lipid content plasma concentrations of apoAI and HDL were elevated but the level of apoAI mRNA was unaltered (Srivastava, 1994) and there was an increase of $20 \%$ in the translation of apoAI mRNA as judged by the amounts of apoAI mRNA in isolated polysomes. These data suggest that there is some translational control of apoAI synthesis but since this was insufficient to account for the 50-60\% increase in plasma apoAI, additional mechanisms, such as reduced protein degradation, may also be important.

\section{Glucose transporters and lipoprotein lipase: evidence for a role of the untranslated regions}

Both glucose transporters and lipoprotein lipase play key roles in the metabolic response to nutrient intake. Not only is the regulation of the amounts of these proteins partly controlled by post-transcriptional mechanisms, but it is emerging that the regulatory elements are present within the UTR of the respective mRNA. Expression of glucose transporter 1 (GLUT1) is regulated at a post-transcriptional level under different pathophysiological conditions (Boado, 1995); for example, glucose deprivation increased GLUT1 mRNA stability without changes in gene transcription (Boado \& Pardridge, 1993). Recent studies suggest that regulatory elements occur in both the $5^{\prime}$ and $3^{\prime}$ UTR with those in the $5^{\prime}$ UTR interacting with certain proteins in a sequence-specific manner to control translational efficiency (Boado et al. 1996) and those in the $3^{\prime}$ UTR binding specific cytosolic proteins and mediating post-transcriptional regulation of GLUT1 gene expression (Dwyer et al. 1996). The fact that the sequence of the GLUT1 mRNA is highly conserved among five different mammalian species, particularly in the $5^{\prime}$ and $3^{\prime}$ UTR (Boado \& Pardridge, 1990) confirms the importance of regulatory elements in these regions. A report suggesting post-transcriptional control of GLUT4 expression (Munoz et al. 1996) leads one to speculate that such mechanisms may occur throughout the GLUT family of proteins.

Lipoprotein lipase mRNA exists in two forms, one of 3.2 kilobases $(\mathrm{kb})$ and one of $3.6 \mathrm{~kb}$; the difference lies in the $3^{\prime}$ UTR with the two forms using different polyadenylation signals and the $3^{\prime}$ UTR being involved in tissue-specific expression (Ranganathan et al. 1995). In adipose tissue both transcripts are expressed, but in muscle and heart only the longer transcript is present. Both transfection and in vitro translation studies indicate that the longer transcript is translated more efficiently resulting in greater synthesis of the protein. Furthermore, regulation of lipoprotein lipase expression by noradrenaline and thyroid hormone in adipocytes also depends on $3^{\prime}$ UTR regulatory elements which control mRNA translation (Kern et al. 1996; Ranganathan et al. 1997); this involves a cytoplasmic repressor protein which binds to the $3^{\prime}$ UTR. In conclusion, the $3^{\prime}$ UTR of lipoprotein lipase both controls tissue-specific differences in expression and allows response to regulatory factors.

\section{Iron and the iron-regulatory element: details of the untranslated region-dependent mechanisms}

The expression of both transferrin receptor and ferritin is controlled by post-transcriptional regulation of their synthesis, and there is now very strong evidence showing clear roles for $3^{\prime} \mathrm{UTR}$ and $5^{\prime} \mathrm{UTR}$ regulatory elements.

Transferrin and its receptor are required for the uptake of $\mathrm{Fe}$ into cells. Transferrin receptor mRNA has five regulatory sequences, named Fe-regulatory elements (IRE) in the $3^{\prime}$ UTR. These sequences are predicted to fold into a stem loop structure (Hershey, 1991) and this structure is required for regulation (Müllner \& Kuhn, 1988). In the absence of $\mathrm{Fe}$, trans-acting repressor proteins, the Fe-regulatory proteins (IRP), bind to these sequences protecting the mRNA from degradation by ribonucleases (Koeller et al. 1989). In the presence of $\mathrm{Fe}$, these repressor proteins are removed from the transferrin receptor mRNA leading to mRNA destabilization, decreased translation of the mRNA, decreased transferrin receptor synthesis and therefore decreased Fe uptake (Madani \& Linder, 1992; Theil, 1994) (Fig. 4). During liver cell proliferation in vivo following partial hepatectomy, this mechanism of post-transcriptional control is capable of fully accounting for the transferrin receptor mRNA induction (Cairo \& Pietrangelo, 1994).

The expression of ferritin, required for storage and detoxification of $\mathrm{Fe}$, is also controlled post-transcriptionally (Cairo et al. 1985) by IRE and IRP (Leibold \& Munro, 1988). In contrast to the transferrin receptor mRNA, where the IRE are in the $3^{\prime}$ UTR and act by regulating mRNA stability, ferritin mRNA has an IRE in the $5^{\prime}$ UTR which regulates translation. When the cellular Fe levels are low the IRP binds to the IRE in the $5^{\prime}$ UTR and represses translation of the mRNA (Fig. 4). In the presence of Fe IRP is removed from the mRNA and ferritin translation is increased to allow storage of Fe (Madani \& Linder, 1992). Additionally, when $\mathrm{Fe}$ is abundant or the IRP is absent, the ferritin IRE region enhances the binding of initiation factors to the mRNA (Dix et al. 1992). The contrasting effects of $\mathrm{Fe}$ on translation of ferritin mRNA and degradation of transferrin receptor mRNA appears to be related to the location of the IRE in different UTR: $5^{\prime}$ UTR in the case of ferritin and $3^{\prime}$ UTR in the case of transferrin receptor (Theil, 1990).

The presence of similar IRE in both transferrin receptor and ferritin mRNA is important because it allows coordinated regulation of synthesis of the two proteins by $\mathrm{Fe}$ concentration. This was the first example of concerted regulation of eukaryotic mRNA (Klausner \& Harford, 1989; Theil, 1990) and illustrates how post-transcriptional control can produce an integrated regulation of different proteins in response to change in intracellular concentrations of a nutrient. There are several known IRE sequences in various species but they are not all the same for ferritin and transferrin receptor, neither in primary nor secondary structure. Nevertheless, they all enable a co-ordinated regulation of Fe uptake, storage and detoxification (Theil, 1994). IRE have been identified in other RNA, such as erythroid 5-aminolevulinate synthase and mitochondrial aconitase, suggesting that $\mathrm{Fe}$ may regulate the expression of a range of genes by post-transcriptional mechanisms (Klausner et al. 1993). 


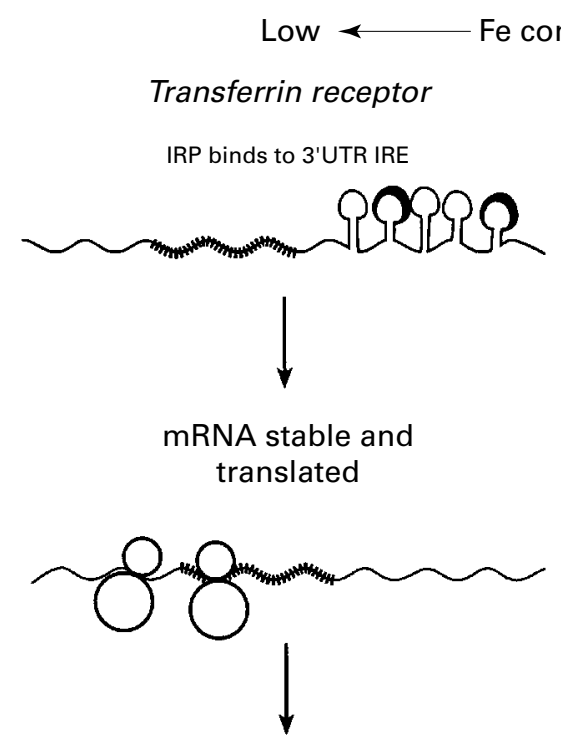

Transferrin receptor synthesis

Ferritin

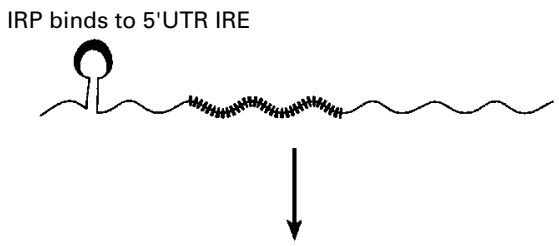

Translation repressed

No ferritin synthesized
$>$ High

Transferrin receptor

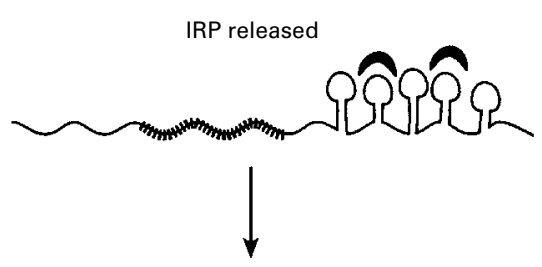

mRNA unstable and degraded

No synthesis of transferrin receptor

\section{Ferritin}

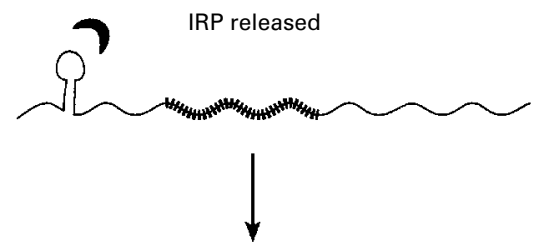

Translation occurs

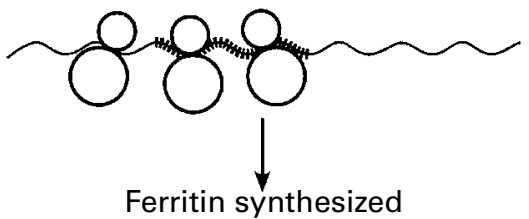

Fig. 4. Regulation of transferrin receptor and ferritin by iron. The diagram illustrates the mechanism by which iron concentrations, through specific iron-regulatory proteins (IRP) and iron-regulatory elements (IRE) in the mRNA, control transferrin receptor and ferritin synthesis. 5'UTR, $5^{\prime}$ untranslated region; 3'UTR, 3'untranslated region.

The IRP are conserved in both structural and functional properties between species (Rothenberg et al. 1990) and exert different effects in different mRNA by the different context of the IRE in the mRNA. In the cases so far examined Fe appears to exert its effects by changing the activity, rather than the amount, of IRP (Hentze et al. 1989; Müllner et al. 1992). One IRP has now been identified as cytoplasmic aconitase (IRP-1) on the basis of amino acid sequence and enzyme activity (Kennedy et al. 1992; Beinert \& Kennedy, 1993), but a second IRP seems distinct in that it has no aconitase activity (Henderson et al. 1993; Guo et al. 1994). Alterations in the Fe-S cluster structure within IRP-1 changed RNA-binding activity (Haile et al. 1992) suggesting that this structure acts as a 'regulatory switch' which alters the binding properties of the protein in response to Fe availability.

NO can mimic the effects of Fe on IRP-1; it activates binding to the IRE, represses ferritin translation and stabilizes transferrin receptor mRNA (Pantopoulos \& Hentze, 1995; Domachowske et al. 1996). Thus it appears that IRP-1 responds not only to Fe but also to NO; therefore in inflammation the generation of $\mathrm{NO}$ in response to cytokines may change cell Fe metabolism by acting at the Fe-S cluster in the IRP-1 protein (Klausner et al. 1993; Mascotti et al. 1995). It has been suggested that other agents, such as superoxide radicals or molecular $\mathrm{O}_{2}$, may also act on this IRP-1 'switch'.

\section{Selenoproteins: role of $3^{\prime}$ untranslated regions in incorporation and channelling of selenium}

The essential micronutrient $\mathrm{Se}$ is incorporated into selenoproteins (e.g. glutathione peroxidases and iodothyronine 
$5^{\prime}$ deiodinases) as selenocysteine. The incorporation of Se occurs during mRNA translation and specific UGA codons are recognized not as stop signals but for insertion of selenocysteine from selenocysteine-tRNA; this requires specific $3^{\prime}$ UTR sequences which form stem-loop structures (Berry et al. 1991, 1993; Shen et al. 1993). Feeding diets of different Se content modifies the activity and amounts of selenoproteins (Burk \& Hill, 1993), and more recent studies have shown that dietary Se supply regulates both the activity of the selenoproteins cytosolic glutathione peroxidase (EC 1.11.1.9; cGSH-Px), phospholipid hydroperoxide glutathione peroxidase (PHGSH-Px) and type 1 iodothyronine $5^{\prime}$ deiodinase (EC 3.8.1.4; IDI) and the abundance of their respective mRNA to different extents (Bermano et al. 1995). There is individual regulation of cGSH-Px, PHGSH-PX and IDI such that there are differences in the sensitivity of the synthesis of each enzyme and the abundance of its mRNA to Se supply, both within a given tissue and between tissues.

Post-transcriptional mechanisms play an important role in this regulation of selenoprotein synthesis in response to altered Se supply. Se deficiency does not affect the rate of transcription of the cGSH-Px, PHGSH-PX or IDI genes in liver nuclei (Bermano et al. 1995) even though there are changes in mRNA abundance and enzyme activity, suggesting that control of the three selenoproteins involves regulation of mRNA stability. In hepatoma cells in culture, Se depletion had no effect on the rate of degradation of the PHGSH-Px mRNA, but decreased that of the cGSH-Px mRNA (Bermano et al. 1996a). This observation suggests that differences in the effect of Se deficiency on stability of the two mRNA can account for the effects of Se deficiency on cGSH-Px and PHGSH-Px in liver. Thus, under conditions of reduced $\mathrm{Se}$ availability there is termination of translation (Chambers et al. 1986; Berry et al. 1991), which leads to destabilization of the mRNA (Bermano et al. 1996a); the differential effects on cGSH-Px and PHGSH-Px mRNA produce a channelling of Se to allow preferential synthesis of a particular selenoprotein.

Differences in the $3^{\prime}$ UTR of the selenoprotein mRNA appear to be critical in determining the relative extent to which the different mRNA are translated (see Fig. 5). First, even when Se supply is adequate, the efficiency of translation of selenoprotein mRNA is affected by the $3^{\prime} \mathrm{UTR}$, as indicated by the observations that the activity of the selenoproteins type I and type III deiodinases are altered by exchanging their native $3^{\prime}$ UTR for those of other selenoproteins (Berry et al. 1991; Salvatore et al. 1995). Second, there is further influence of the $3^{\prime}$ UTR when Se supply is low: translation of chimaeric constructs containing the IDI coding region linked to PHGSH-Px $3^{\prime}$ UTR is affected less by low Se conditions than translation of IDI linked to the glutathione peroxidase 3'UTR (Bermano et al. 1996b). This suggests that when Se supply is limiting the $3^{\prime}$ UTR of cGSH-Px is less efficient at maintaining translation than that of PHGSH-Px and this probably reflects different abilities to form a complex with selenocysteine-tRNA and appropriate protein factors. In turn, this could involve subtle differences in stem-loop structures and different strengths of complex formation when either selenocysteine tRNA or an mRNA-binding protein (elongation factor) is limiting so that the available selenocysteine is utilized for preferential synthesis of a particular selenoprotein. Recently an mRNAbinding protein that binds to the stem-loop structure of cGSH-Px mRNA has been isolated (Shen et al. 1995) but it is not known if the synthesis of this protein, or the affinity for the stem-loop, changes in Se-deficient conditions. Whatever the detailed mechanism, it is clear that the 3'UTR-based Se-insertion mechanism responds to $\mathrm{Se}$ supply and channels the available Se for synthesis of particular selenoproteins.

\section{Metallothionein: translational control and mRNA localization}

MT exists in several isoforms (MT-1, MT-2 etc.) which bind metals such as $\mathrm{Zn}, \mathrm{Cd}$ and $\mathrm{Cu}$. The precise function(s) of the MT isoforms remains unknown, although they are thought to transport metals and maintain metal homeostasis in the cell, as well as possibly having an antioxidant function in protecting DNA from damage (Bremner \& Beattie, 1990). Following administration of metals there is an induction of MT isoforms in liver and kidney. This involves increased gene transcription but there is also evidence for post-transcriptional control of MT synthesis. For example, during development MT protein abundance does not parallel mRNA abundance (Andersen et al. 1983). More recently it has been shown that, after metal administration, there is induction of both MT-1 and MT-2 mRNA in rat liver but only the MT-1 isoform shows an increased amount of protein, indicating that there is differential control of translation of the two isoforms (Vasconcelos et al. 1996). Similarly, MT-2, but not MT-1, is posttranscriptionally regulated in fish (Scudiero et al. 1997). The reason for this differential regulation of the two isoforms is not known but it is possible that the two isoforms have different functions and/or different subcellular compartmentation.

Recent data suggest that indeed there may be some compartmentation of the isoforms and that, furthermore, this involves localization of the mRNA. In rat hepatoma cells the mRNA for MT-1 has a perinuclear location and is associated with the cytoskeleton, whereas the mRNA for MT-2 shows less association (Mahon et al. 1995). Thus, it appears that the mRNA for these two isoforms are compartmentalized, suggesting that the proteins are synthesized in different subcellular sites. Expression of hybrid gene constructs in transfected cells has shown that localization of MT-1 mRNA is lost on exchange of the $3^{\prime}$ UTR for that of cGSH-Px, and the $3^{\prime}$ UTR of MT-1 mRNA itself is able to target $\beta$-globin transcripts to the perinuclear cytoplasm and the cytoskeleton (Mahon et al. 1997). Therefore the $3^{\prime}$ UTR of MT-1 mRNA determines the site of MT-1 synthesis. The role of this targeting is still unclear, but it may be important in compartmentation of MT within the cell. Under certain circumstances, such as during cell proliferation, MT is found in the nucleus (Tohyama et al. 1993). The mRNA for several nuclear proteins are associated with the cytoskeleton or localized in the perinuclear cytoplasm (Hesketh, 1996a), and so it is probable that the targeting of MT-1 mRNA to the cytoskeleton in the perinuclear cytoplasm is related to the compartmentation of the MT-1 protein. 


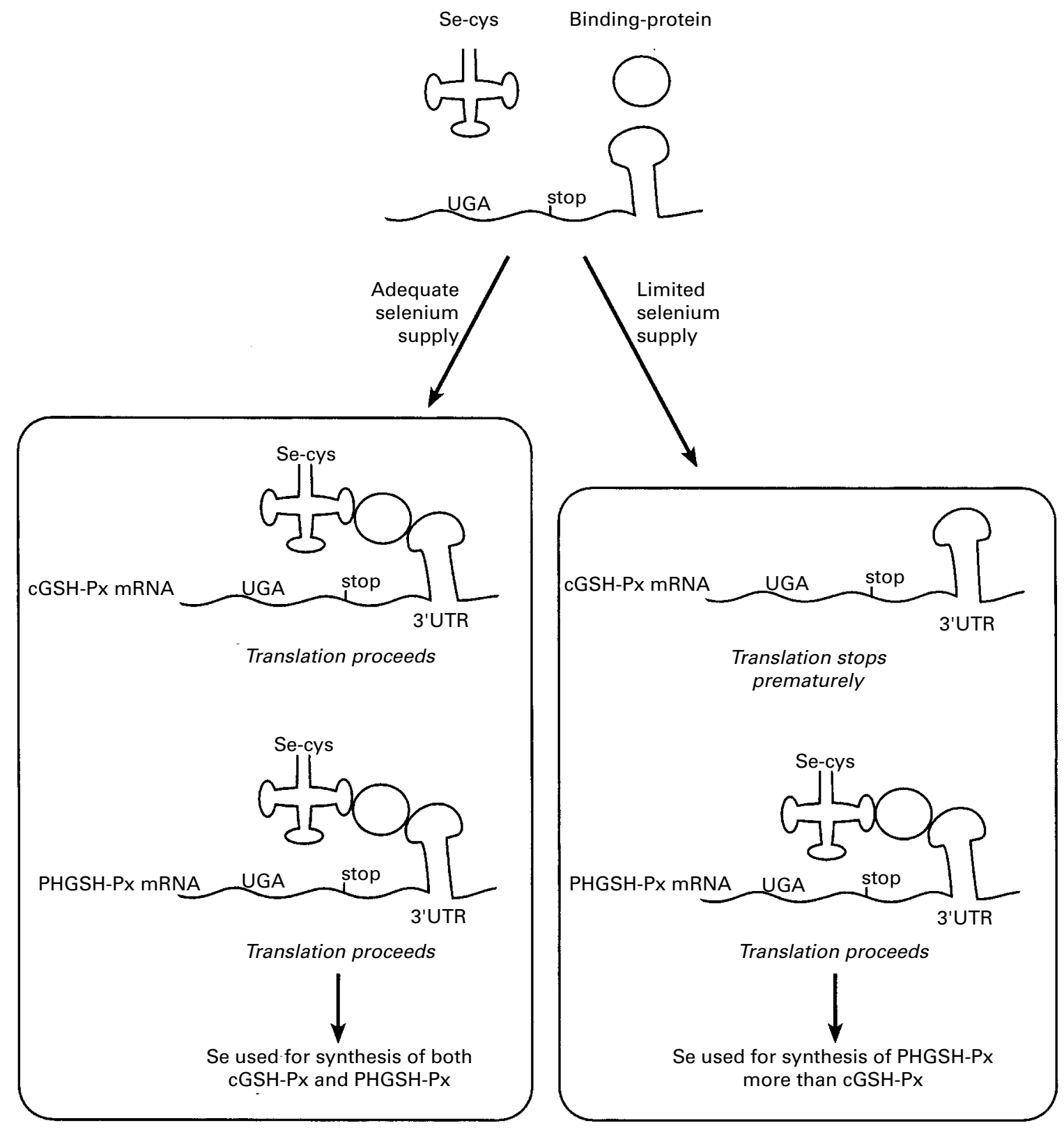

Fig. 5. Channelling of selenium for preferential synthesis of a particular selenoprotein. The diagram illustrates schematically how the posttranscriptional mechanism for incorporation of selenium into selenoproteins responds to altered selenium supply by allowing preferential translation of phospholipid hydroperoxide glutathione peroxidase (PHGSH-Px) mRNA rather than cytosolic glutathione peroxidase (cGSH-Px) mRNA. This results in preferential synthesis of one selenoprotein rather than the other. $3^{\prime} U T R, 3^{\prime}$ untranslated region; Se-cys, selenocysteine.

\section{3'Untranslated region signals, $m R N A$ localization and metabolic compartmentation}

The localization and targeting of MT-1 mRNA illustrates how, in a nutritional context, mRNA targeting by the $3^{\prime}$ UTR may provide a mechanism for the compartmentation of proteins which bind or metabolize nutrients. Nutrients must not only be delivered to the cell but also to the correct compartment within the cell, whether this be a cytoplasmic domain or an organelle: post-transcriptional control of the site of synthesis of specific proteins which influence nutrient metabolism, compartmentation and function may provide a basis of such nutrient channelling. As discussed earlier, targeting of MT isoform mRNA may allow compartmentation of the protein isoforms, as with actin and creatine kinase isoforms (Kislauskis et al. 1993; Wilson et al. 1995) and possibly targeting of the protein to the nucleus.

The expression of retargeted mRNA in transfected cells does not prevent translation of the mRNA to synthesize the proteins. Thus, the modification of targeting signals to alter the site of synthesis of proteins provides opportunities to study the effects of mRNA relocalization on protein distribution. The production of such stably transfected cell lines will allow studies of the roles of specific proteins in 
Table 1. Nutrition, post-transcriptional control and regulatory elements in untranslated regions (UTR)

\begin{tabular}{|c|c|c|c|}
\hline Gene & Nutritional factor & Control point & Regulatory element \\
\hline Ferritin & $\mathrm{Fe}$ & Translation & $5^{\prime}$ UTR \\
\hline Transferrin receptor & $\mathrm{Fe}$ & Stability & $3^{\prime}$ UTR \\
\hline $\begin{array}{l}\text { Cytoplasmic glutathione } \\
\text { peroxidase }\end{array}$ & Se & Translation & $3^{\prime}$ UTR \\
\hline $\begin{array}{l}\text { Phospholipid hydroperoxide } \\
\text { glutathione peroxidase }\end{array}$ & $\mathrm{Se}$ & Translation & $3^{\prime} U T R$ \\
\hline Metallothionein-1 & - & Localization & $3^{\prime}$ UTR \\
\hline Metallothionein-2 & $\mathrm{Zn}$ & Translation(?) & $?$ \\
\hline Glucose transporter-1 & - & Translation & $5^{\prime}$ UTR \\
\hline Lipoprotein lipase & $?$ & Translation & $3^{\prime}$ UTR \\
\hline c-myc & Amino acid supply & Stability & $?$ \\
\hline c-myc & - & Localization & $3^{\prime}$ UTR \\
\hline Argininosuccinate lyase & - & Localization & $?$ \\
\hline Creatine kinase & - & Localization & 3'UTR \\
\hline Retinol-binding protein & Vitamin A & Stability & $?$ \\
\hline Apolipoprotein CIII & Hyperlipidaemia & $?$ & 3'UTR \\
\hline
\end{tabular}

nutrient compartmentation; for example, the function of MT in the nucleus and whether the site of synthesis of the retinoic acid binding protein CRABP-1, which has been found in the nucleus and has been suggested to transport retinoic acid (Gustafason et al. 1996), is critical for its function. Such mechanisms may provide novel interactions between nutrition and gene expression. For example, differences in a fundamental mechanism of nutrient compartmentation could lead to altered nutritional requirements.

The spatial organization of protein synthesis within the cell and local synthesis of certain proteins has major implications for the study of protein synthesis in all tissues. For example, it is relevant to muscle because of its possible involvement in myofibrillar protein turnover (Hesketh, $1996 b$ ) and it concerns tissues with obvious polarity such as epithelia and secretory tissues such as the mammary gland where there is nutrient-driven regulation of export proteins. Compartmentation may influence the interpretation of protein synthetic measurements and indeed some kinetic data are compatible with certain proteins being synthesized from different amino acid pools (Connell et al. 1997). mRNA localization also has the potential to contribute to the compartmentation of enzymes and metabolic pathways. This has been elegantly demonstrated in the case of urea cycle enzymes such as argininosuccinate lyase (Cohen, 1995, 1996); both the enzymes and their mRNA are localized in the cytoplasm surrounding the mitochondria. This compartmentation allows reutilization of the 'catalytic' ornithine so that the cycle is not dependent on changes in cellular concentrations and thus insensitive to nutrient supply.

\section{Conclusions and perspectives: untranslated regions as sites of nutritional regulation}

It is now clear that post-transcriptional control is important in determining the synthesis of specific proteins. This is also exemplified in a number of nutrient-related systems, either by regulation of synthesis of specific proteins by nutrients or, alternatively, by the regulation of proteins which have important roles in nutrient metabolism. This reveals that the interactions between nutrition and gene expression are not restricted to the study of how nutrition interacts with the genome and gene transcription but also how nutrition affects mRNA.

This has two implications for studies of gene expressionnutrition interaction. First, the possibility that posttranscriptional interactions occur should always be considered. Second, since nutrition can regulate mRNA translation and stability, mRNA abundances may not reflect amounts of protein or rates of synthesis; therefore, observed changes in the abundance of a certain mRNA may not be followed by changes in amounts of the corresponding protein, or a lack of alteration in mRNA abundance may not mean there is no change in its protein. Thus, in order to relate, confidently, nutritional status to gene expression mRNA measurements should be accompanied by measurements of the protein product.

In certain specific cases, for example $\mathrm{Fe}$ and $\mathrm{Se}$, posttranscriptional regulation plays a central role. However, in general, more information is required to assess the relative importance of post-transcriptional control relative to transcriptional and post-translational control in nutrient-gene interactions. Our view is that the role of different control mechanisms will vary from gene to gene. Post-transcriptional control of mRNA stability, translation and localization results in the regulation of expression of those genes becoming, at least partly, a cytoplasmic event. Regulation of gene expression in the cytoplasm offers certain advantages to the cell or organism. First, such control could respond directly and rapidly to cytoplasmic metabolite or nutrient concentrations rather than indirectly through nuclear transcription factors. Second, it allows regulatory mechanisms to use proteins with dual functions as both cytoplasmic enzymes and mRNA-binding proteins. Third, it allows development of mechanisms to localize mRNA and their translation, and thus regulate the sites of protein synthesis and delivery of newly-synthesized proteins; this has the potential to provide mechanisms to channel nutrients.

In those cases where details are known about the mechanism of nutritional effects on post-transcriptional control, the regulatory sequences involved have usually been found in the $5^{\prime}$ or $3^{\prime}$ UTR (Table 1 ). This reflects the growing realization that UTR-based regulatory elements and RNAbinding proteins play a major role in post-transcriptional 
control (Fig. 3, Table 1). In particular, it is now evident that $3^{\prime}$ UTR are not lengths of redundant nucleotides but, on the contrary, are highly important parts of mRNA which contain a variety of regulatory elements that play a crucial role in determining the fate of individual mRNA within the cytoplasm. The number of examples in the literature where gene expression is controlled via such $3^{\prime}$ UTR elements is increasing rapidly and it should be considered that this type of control exerts a major influence over the expression of many genes.

Furthermore, these UTR-based control mechanisms are of considerable relevance to nutrition: in several cases nutritional factors regulate gene expression through UTR elements and in other cases nutritionally-relevant proteins are regulated in this way. For example, the spatial organization of protein synthesis, the channelling of Se for preferential synthesis of one selenoprotein rather than another, and the regulation of the synthesis of the transferrin receptor and ferritin by the cellular Fe concentration, all involve UTR-based mechanisms. The regulation of other nutritionally-related mRNA (e.g. lipoprotein lipase and MT-1 mRNA) by $3^{\prime}$ UTR elements, the considerable length of $3^{\prime}$ UTR sequences in general, their conserved regions and the identification of regulatory elements within these regions shows that further studies on $3^{\prime}$ UTR and RNAbinding proteins have the potential to produce many new insights into the interaction between nutrition and gene expression.

At present, nutritional regulation of post-transcriptional events is primarily a subject of fundamental research but in the long term it has the potential for considerable clinical relevance, as shown by the observation that the polymorphisms found in the $3^{\prime} \mathrm{UTR}$ of the apoCIII mRNA influence resistance and susceptibility to hyperlipidaemia (Dammerman et al. 1993). This illustrates the potential of future research to define the extent to which nutrition influences gene expression through post-transcriptional control and how individual variation in these regulatory mechanisms may alter nutritional requirements. These questions are currently being addressed using a combination of recombinant DNA technology and transfection into cells in culture, but the increasing availability of transgenic animals (Hall, 1997) should allow us to build on these approaches to define the interactions between UTR and nutrition.

\section{Acknowledgement}

The authors' work was supported by the Scottish Office Agriculture Environment and Fisheries Department.

\section{References}

Amara SG, Jonas V, Rosenfeld MG, Ong ES \& Evans RM (1982) Alternative RNA processing in calcitonin gene expression generates mRNAs encoding different polypeptide products. Nature 298, 240-244.

Andersen RD, Piletz JE, Birren BW \& Herschman HR (1983) Levels of metallothionein messenger RNA in foetal, neonatal and maternal rat liver. European Journal of Biochemistry 131, 497-500.

Baum CL, Teng BB \& Davidson NO (1990) Apolipoprotein B messenger RNA editing in the rat liver. Modulation by fasting and refeeding a high carbohydrate diet. Journal of Biological Chemistry 265, 19263-19270.

Beinert H \& Kennedy MC (1993) Aconitase, a two-faced protein: enzyme and iron regulatory factor. FASEB Journal 7, 14421449.

Bermano G, Arthur JR \& Hesketh JE (1996a) Selective control of cytosolic glutathione peroxidase and phospholipid hydroperoxide glutathione peroxidase mRNA stability by selenium supply. FEBS Letters 387, 157-160.

Bermano G, Arthur JR \& Hesketh JE (1996b) Role of the $3^{\prime}$ untranslated region in the regulation of cytosolic glutathione peroxidase and phospholipid hydroperoxide glutathione gene expression by selenium supply. Biochemical Journal 320, 425430.

Bermano G, Nicol F, Dyer J, Sunde RA, Beckett GJ, Arthur JR \& Hesketh JE (1995) Tissue-specific regulation of selenoenzyme gene expression during selenium deficiency in rats. Biochemical Journal 311, 425-430.

Berry MJ, Banu L, Harney JW \& Larsen PR (1993) Functional characterization of the eukaryotic SECIS elements with direct selenocysteine insertion at UGA codons. EMBO Journal 12, 3315-3322.

Berry MJ, Banu L \& Larsen PR (1991) Recognition of UGA as a selenocysteine codon in type I deiodinase requires sequences in the 3'untranslated region. Nature 349, 438-440.

Boado RJ (1995) Brain-derived peptides regulate the steady-state levels and increase stability of the blood-brain barrier GLUT1 glucose transporter mRNA. Neuroscience Letters 197, 179-182.

Boado RJ \& Pardridge WM (1990) Molecular cloning of bovine blood-brain barrier glucose transporter cDNA and demonstration of phylogenetic conservation of the $5^{\prime}$ untranslated region. Molecular and Cellular Neuroscience 1, 224-232.

Boado RJ \& Pardridge WM (1993) Glucose deprivation causes posttranscriptional enhancement of brain capillary endothelial glucose transporter gene expression via GLUT1 mRNA stability. Journal of Neurochemistry 60, 2290-2296.

Boado RJ, Tsukamoto H \& Pardridge WM (1996) Evidence for translational control elements within the $5^{\prime}$ untranslated region of GLUT1 glucose transporter mRNA. Journal of Neurochemistry 67, 1335-1343.

Bremner I \& Beattie JH (1990) Metallothioneins and the trace minerals. Annual Reviews of Nutrition 10, 63-83.

Burk RF \& Hill KE (1993) Regulation of selenoproteins. Annual Reviews of Nutrition 13, 65-81.

Cairo G, Bardella L, Schiaffonati L, Arosio P, Levi S \& BernelliZazzera A (1985) Multiple mechanisms of iron-induced ferritin synthesis in HeLa cells. Biochemical and Biophysical Research Communications 133, 314-321.

Cairo G \& Pietrangelo A (1994) Transferrin receptor gene expression during rat liver regeneration: evidence for posttranscriptional regulation by iron regulatory factor $\mathrm{B}$, a second iron-responsive element-binding protein. Journal of Biological Chemistry 269, 6405-6409.

Chambers I, Frampton J, Goldfarb P, Affara N, McBain W \& Harrison PR (1986) The structure of the mouse glutathione peroxidase gene: the selenocysteine in the active site is encoded by the termination codon, TGA. EMBO Journal 5, 1221-1227.

Chen C-YA \& Shyu A-B (1995) AU-rich elements: characterization and importance in mRNA degradation. Trends in Biochemical Sciences 20, 465-470.

Choi JW \& Peffley DM (1995) 3'Untranslated sequences mediate post-transcriptional regulation of 3-hydroxy-3-methylglutarylCoA reductase mRNA by 25 -hydroxycholesterol. Biochemical Journal 307, 233-238.

Chu E, Voeller D, Koeller DM, Drake JC, Takimoto CH, Maley GF, Maley F \& Allegra CJ (1993) Identification of an RNA 
binding site for human thymidylate synthase. Proceedings of the National Academy of Sciences USA 90, 517-521.

Clarke SD \& Abraham S (1992) Gene expression: nutrient control of pre- and post-transcriptional events. FASEB Journal 6, 31463152.

Clarke SD, Armstrong MK \& Jump DB (1990) Nutritional control of rat liver fatty acid synthase and S14 mRNA abundance. Journal of Nutrition 120, 218-224.

Coccia EM, Cicala C, Charlesworth A, Ciccarelli C, Rossi GB, Philipson L \& Sorrentino V (1992) Regulation and expression of a growth arrest-specific gene (gas5) during growth, differentiation and development. Molecular and Cellular Biology 12, 3514-3521.

Cohen N (1995) Argininosuccinate synthetase and argininosuccinate lyase are localised around mitochondria: an immunocytochemical study. Journal of Cellular Biochemistry 60, 334-340.

Cohen N (1996) Intracellular localisation of the mRNAs of argininosuccinate synthetase and argininosuccinate lyase around mitochondria, visualised by high-resolution in situ reverse transcription-polymerase chain reaction. Journal of Cellular Biochemistry 61, 81-96.

Connell A, Calder AG, Anderson SE \& Lobley GE (1997) Hepatic protein synthesis in the sheep: effect of intake as monitored by use of stable-isotope-labelled glycine, leucine and phenylalanine. British Journal of Nutrition 77, 255-271.

Dammerman M, Sandkuijl LA, Halaas JL, Chung W \& Breslow JI (1993) An apolipoprotein CIII haplotype protective against hypertriglyceridemia is specified by promoter and 3' untranslated region polymorphisms. Proceedings of the National Academy of Sciences USA 90, 4562-4566.

Dix DJ, Lin P-N, Kimata Y \& Theil EC (1992) The iron-regulatory region of ferritin mRNA is also a positive control element for ironindependent translation. Biochemistry 31, 2818-2822.

Domachowske JB, Rafferty SP, Singhania N, Mardiney M \& Malech HL (1996) Nitric oxide alters the expression of $\gamma$ globin, H-ferritin and transferrin receptor in human K562 cells at the posttranscriptional level. Blood 88, 2980-2988.

Dozin B, Rall JE \& Nikodem VM (1986) Tissue-specific control of malic enzyme activity and messenger RNA levels by a high carbohydrate diet. Proceedings of the National Academy of Sciences USA 83, 4705-4709.

Dwyer KJ, Boado RJ \& Pardridge WM (1996) Cis-element/ cytoplasmic protein interaction within the $3^{\prime}$ untranslated region of GLUT1 glucose transporter mRNA. Journal of Neurochemistry 66, 449-458.

Fleming JV, Hay SM, Harries DN \& Rees WD (1998) Expression of growth arrest genes (gas and gadd) in F9 embryonic carcinoma cells: the effect of growth arrest on differentiating cells. Biochemical Journal 330, 573-579.

Foufelle F, Perdereau D, Gouhot B, Ferre P \& Girard J (1992) Effect of diets rich in medium-chain and long-chain triglycerides on lipogenic-enzyme gene expression in liver and adipose tissue of the weaned rat. European Journal of Biochemistry 208, 381-387.

Fritz RS, Stumpo DJ \& Kletzien RF (1986) Glucose-6-phosphate dehydrogenase mRNA sequence abundance in primary cultures of rat hepatocytes. Effect of insulin and dexamethasone. Biochemical Journal 237, 617-619.

Galili G, Kawata EE, Smith LD \& Larkins BA (1988) Role of the $3^{\prime}$-poly (A) sequence in translational regulation of mRNAs in Xenopus laevis oocytes. Journal of Biological Chemistry 263, 5764-5770.

Garrett JE, Collard MW \& Douglass JO (1989) Translational control of germ cell-expressed mRNA imposed by alternative splicing: opioid peptide gene expression in rat testis. Molecular and Cellular Biology 9, 4381-4389.
Gavis ER \& Lehmann R (1994) Translational regulation of nanos by RNA localization. Nature 369, 315-318.

Gofman JW, Young W \& Tandy R (1966) Ischemic heart disease, atherosclerosis and longevity. Circulation 34, 679-697.

Goldberg A \& Schonfeld G (1985) Effects of diet on lipoprotein metabolism. Annual Review of Nutrition 5, 195-212.

Gray NK \& Hentze MW (1994) Regulation of protein synthesis by mRNA structure. Molecular Biology Reports 19, 195-200.

Guo B, Yu Y \& Leibold EA (1994) Iron regulates cytoplasmic levels of a novel iron-responsive element-binding protein without aconitase activity. Journal of Biological Chemistry 269, 24252-24260.

Gustafson A-L, Donovan M, Annerwall E, Dencker L \& Eriksson U (1996) Nuclear import of cellular retinoic acid-binding protein type I in mouse embryonic cells. Mechanisms in Development 58, 27-38.

Haile DJ, Rouault TA, Tang CK, Chin J, Harford JB \& Klausner RD (1992) Reciprocal control of RNA-binding and aconitase activity in the regulation of the iron-responsive element binding protein: role of the iron-sulfur cluster. Proceedings of the National Academy of Sciences USA 89, 7536-7540.

Hall J (1997) From animals in the service of nutrition ... to the potential of biotechnology. British Journal of Nutrition 78, S125-S133.

Henderson BR, Seiser C \& Kuhn LC (1993) Characterization of a second RNA-binding protein in rodents with specificity for ironresponsive elements. Journal of Biological Chemistry 268, 27327-27334.

Hentze MW (1995) Translational regulation: versatile mechanisms for metabolic and developmental control. Current Opinions in Cell Biology 7, 393-398.

Hentze MW, Rouault TA, Harford JB \& Klausner RD (1989) Oxidation-reduction and the molecular mechanism of a regulatory RNA-protein interaction. Science 244, 357-359.

Hershey JWB (1991) Translational control in mammalian cells. Annual Reviews of Biochemistry 60, 717-755.

Hesketh JE (1994) Translation on the cytoskeleton - a mechanism for targeted protein synthesis. Molecular Biology Reports 19, $233-243$.

Hesketh JE (1996a) Sorting messenger RNAs in the cytoplasm: mRNA localization and the cytoskeleton. Experimental Cell Research 225, 219-236.

Hesketh JE (1996b) Compartmentation of protein synthesis, mRNA targeting and c-myc expression during muscle hypertrophy and growth. In Molecular Physiology of Growth. Society of Experimental Biology Seminar Series no. 60, pp. 99-118 [PT Loughna and JM Pell, editors]. Cambridge: Cambridge University Press.

Hesketh JE, Campbell GP, Piechaczyk M \& Blanchard J-M (1994) Targeting of c-myc and $\beta$-globin coding sequences to cytoskeletal-bound polysomes by c-myc $3^{\prime}$ untranslated region. Biochemical Journal 298, 143-148.

Hovland R, Campbell GP, Pryme IF \& Hesketh JE (1995) The mRNAs for cyclin A, c-myc and ribosomal proteins L4 and S6 are associated with cytoskeletal-bound polysomes in HepG2 cells. Biochemical Journal 310, 193-196.

Hsu H-Y, Nicholson AC \& Hajjar DP (1996) Inhibition of macrophage scavenger receptor activity by tumor necrosis factor- $\alpha$ is transcriptionally and post-transcriptionally regulated. Journal of Biological Chemistry 271, 7767-7773.

Izaurralde E \& Mattaj IW (1995) RNA export. Cell 81, 153-159. Jackson RJ \& Standart N (1990) Do the poly(A) tail and $3^{\prime}$ untranslated region control mRNA translation? Cell 62, $15-24$.

Januszeski MM \& Gurr JA (1991) Differential translatability in vitro of multiple messenger RNAs encoding the $\beta$-subunit of mouse thyrotropin. Molecular Endocrinology 5, 493-502. 
Katsurada A, Iritani N, Fukuda H, Matsumura Y, Nishimoto N, Noguchi T \& Tanaka T (1990a) Effects of nutrients and hormones on transcriptional and post-transcriptional regulation of acetyl-CoA carboxylase in rat liver. Journal of Nutrition $\mathbf{1 9 0}$, 435-441.

Katsurada A, Iritani N, Fukuda H, Matsumura Y, Nishimoto N, Noguchi $\mathrm{T} \&$ \& Tanaka T (1990b) Effects of nutrients and hormones on transcriptional and post-transcriptional regulation of fatty acid synthase in rat liver. European Journal of Biochemistry 190, 427-433.

Kennedy MC, Mueller-Mende L, Blondin GA \& Bienert H (1992) Purification and characterization of cytosolic aconitase from beef liver and its relationship to the iron-responsive element binding protein. Proceedings of the National Academy of Sciences USA 89, 11730-11734.

Kern PA, Ranganathan G, Yukht A, Ong JM \& Davis RC (1996) Translational regulation of lipoprotein lipase by thyroid hormone is via a cytoplasmic repressor that interacts with the 3 ' untranslated region. Journal of Lipid Research 37, 2332-2340.

Kislauskis EH, Li Z, Taneja KL \& Singer RH (1993) Isoformspecific $3^{\prime}$ untranslated sequences sort $\alpha$-cardiac and $\beta$-cytoplasmic actin messenger RNAs to different cytoplasmic compartments. Journal of Cell Biology 123, 165-172.

Klausner RD \& Harford JB (1989) Cis-trans models for posttranscriptional gene regulation. Science 246, 870-872.

Klausner RD, Rouault TA \& Harford JB (1993) Regulating the fate of mRNA: the control of cellular iron metabolism. Cell 72, 1928.

Kletzien RF, Prostko CP, Stumpo DJ, McClung JK \& Dreher KL (1985) Molecular cloning of DNA sequences complementary to rat liver glucose-6-phosphate dehydrogenase messenger RNA. Nutritional regulation of messenger RNA levels. Journal of Biological Chemistry 260, 5621-5624.

Koeller DM, Casey JL, Hentze MW, Gerhardt EM, Chan L-NL, Klausner RD \& Harford JB (1989) A cytosolic protein binds to structural elements within the iron regulatory region of the transferrin receptor mRNA. Proceedings of the National Academy of Sciences USA 86, 3574-3578.

Kozak M (1992) Regulation of translation in eukaryotic systems. Annual Reviews of Cell Biology 8, 197-225.

Leibold EA \& Munro HN (1988) Cytoplasmic protein binds in vitro to a highly conserved sequence in the $5^{\prime}$ untranslated region of ferritin heavy- and light-subunit mRNAs. Proceedings of the National Academy of Sciences USA 85, 2171-2175.

Leighton JK, Joyner J, Zamarripa J, Deines M \& Davis RA (1990) Fasting decreases apolipoproteinB messenger RNA editing and secretion of small molecular weight $A p o B$ by rat hepatocytes - evidence that the total amount of ApoB secreted is regulated post- transcriptionally. Journal of Lipid Research 31, 1663-1668.

Little E, Ramakrishnan M, Roy B, Gazit G \& Lee AS (1994) The glucose-regulated proteins (GRP78 and GRP94): functions, gene regulation and applications. Critical Review in Eukaryotic Gene Expression 4, 1-18.

McCarthy JEG \& Kollmus H (1995) Cytoplasmic mRNA-protein interactions in eukaryotic gene expression. Trends in Biochemical Sciences 20, 191-197.

Madani N \& Linder MC (1992) Differential effects of iron and inflammation on ferritin synthesis on free and membrane-bound polyribosomes of rat liver. Archives of Biochemistry and Biophysics 299, 206-213.

Mahon P, Beattie JH, Glover LA \& Hesketh JE (1995) Localisation of metallothionein isoform mRNAs in rat hepatoma (H4) cells. FEBS Letters 373, 76-80.

Mahon P, Partridge K, Beattie JH, Glover LA \& Hesketh JE (1997) The $3^{\prime}$ untranslated region plays a role in the targeting of metallothionein-1 mRNA to the perinuclear cytoplasm and cytoskeletal-bound polysomes. Biochimica et Biophysica Acta 1358, 153-162.

Mascotti DP, Rup D \& Thach RE (1995) Regulation of iron metabolism: translational effects mediated by iron, heme, and cytokines. Annual Reviews of Nutrition 15, 239-261.

Mercer JFB \& Wake SA (1985) An analysis of the rate of metallothionein mRNA poly(A)-shortening using RNA blot hybridisation. Nucleic Acids Research 13, 7929-7943.

Morley SJ (1994) Signal transduction mechanisms in the regulation of protein synthesis. Molecular Biology Reports 19, 221-231.

Müllner E \& Kuhn LC (1988) A stem-loop in the $3^{\prime}$ untranslated region mediates iron-dependent regulation of transferrin receptor mRNA stability in the cytoplasm. Cell 53, 815-825.

Müllner EW, Rothenberger S, Muller AM \& Kuhn LC (1992) In vivo and in vitro modulation of the mRNA-binding activity of iron-regulatory factor: tissue distribution and effects of cell proliferation, iron levels and redox state. European Journal of Biochemistry 208, 597-605.

Munoz P, Chillaron J, Camps M, Castello A, Furriols M, Testar X, Palacin M \& Zorzano A (1996) Evidence for posttranscriptional regulation of GLUT4 expression in muscle and adipose tissue from streptozotocin-induced diabetic and benfluorex-treated rats. Biochemical Pharmacology 52, 1665-1673.

Nur T, Sela I, Webster NJG \& Madar Z (1995) Starvation and refeeding regulate glycogen synthase gene expression in rat liver at a post-transcriptional level. Journal of Nutrition 125, 24572462.

Pantopoulous K \& Hentze MW (1995) Nitric oxide signalling to iron-regulatory protein: direct control of ferritin mRNA translation and transferrin receptor mRNA stability in transfected fibroblasts. Proceedings of the National Academy of Sciences USA 92, 1267-1271.

Prostko CR, Fritz RS \& Kletzien RF (1989) Nutritional regulation of hepatic glucose-6-phosphate dehydrogenase. Biochemical Journal 258, 295-299.

Ranganathan G, Ong JM, Yukht A, Saghizadeh M, Simsolo RB, Pauer A \& Kern PA (1995) Tissue-specific expression of lipoprotein lipase - effect of $3^{\prime}$ untranslated region on translation. Journal of Biological Chemistry 270, 7149-7155.

Ranganathan G, Vu D \& Kern PA (1997) Translational regulation of lipoprotein lipase by epinephrine involves a trans-acting protein interacting with the $3^{\prime}$ untranslated region. Journal of Biological Chemistry 272, 2515-2519.

Richter JD (1991) Translational control during early development. BioEssays 13, 179-183.

Rosenwald IB, Kaspar R, Rousseau D, Gehrke L, Leboulch P, Chen J-J, Schmidt EV, Sonenberg N \& London IM (1995) Eukaryotic translation initiation factor 4E regulates expression of cyclin D1 at transcriptional and post-transcriptional levels. Journal of Biological Chemistry 270, 21176-21180.

Rothenberg S, Mullner EW \& Kuhn LC (1990) The mRNAbinding protein which controls ferritin and transferrin receptor expression is conserved during evolution. Nucleic Acids Research 18, 1175-1179.

Sachs AB \& Davis RW (1990) Translation initiation and ribosomal biogenesis: involvement of a putative rRNA helicase and RPL46. Science 247, 1077-1079.

Salvatore D, Low SC, Berry M, Maia AL, Harney JW, Croteau W, St Germain DL \& Larsen PR (1995) Type III iodothyronine deiodinase: cloning, in vitro expression, and functional analysis of the placental selenoenzyme. Journal of Clinical Investigation 96, 2421-2437.

Scott J (1989) The molecular and cell biology of apolipoprotein B. Molecular Biology and Medicine 6, 65-80.

Scudiero R, Carginale V, Riggio M, Capasso C, Capasso A, Kille P, Prisco G \& Parisi E (1997) Difference in hepatic metallothionein content in Antarctic red-blooded and haemoglobinless fish: 
undetectable metallothionein levels in haemoglobinless fish is accompanied by accumulation of untranslated metallothionein mRNA. Biochemical Journal 322, 207-211.

Shen Q, Chu F-F \& Newburger PE (1993) Sequences in the 3 'untranslated region of the human cellular glutathione peroxidase gene are necessary and sufficient for selenocysteine incorporation at the UGA codon. Journal of Biological Chemistry 268, 11463-11469.

Shen Q, McQuilkin PA \& Newburger PE (1995) RNA-binding proteins that specifically recognize the selenocysteine insertion sequence of human cellular glutathione peroxidase mRNA. Journal of Biological Chemistry 270, 30448-30452.

Sorci-Thomas M, Wilson MD, Johnson FL, Williams DL \& Rudel LL (1989) Studies on the expression of genes encoding apolipoprotein B-100 and B-48 and the low density lipoprotein receptor in nonhuman primates. Journal of Biological Chemistry 264, 9039-9045.

Spindler SR, Crew MD, Mote PL, Grizzle JM \& Walford RL (1990) Dietary energy restriction in mice reduces hepatic expression of glucose-regulated protein 78 (BiP) and 94 mRNA. Journal of Nutrition 120, 1412-1417.

Srivastava RAK (1994) Saturated fatty acid, but not cholesterol, regulates apolipoprotein AI gene expression by posttranscriptional mechanism. Biochemistry and Molecular Biology International 34, 393-402.

Srivastava RAK, Jiao S, Tang J, Pfleger B, Kitchens RT \& Schonfeld G (1991) In vivo regulation of low density lipoprotein receptor and apolipoprotein B gene expression by dietary fat and cholesterol in inbred strains of mice. Biochimica et Biophysica Acta 1086, 29-43.

Srivastava RAK, Tang J, Krul ES, Pfleger B, Kitchens RT \& Schonfeld G (1992) Dietary fatty acids and dietary cholesterol differ in their effect on the in vivo regulation of apolipoprotein $\mathrm{AI}$ and AII gene expression in inbred strains of mice. Biochimica et Biophysica Acta 1125, 251-256.

Straus DS, Burke EJ \& Marten NW (1993) Induction of insulinlike growth factor binding protein-1 gene expression in liver of protein-restricted rats and in rat hepatoma cells limited for a single amino acid. Endocrinology 132, 1090-1100.

Strobl W, Gorder NL, Fienup GA, Lin-Lee YC, Gotto AM \& Patsch W (1989) Effect of sucrose diet on apolipoprotein biosynthesis in rat liver. Increase in apolipoprotein E gene transcription. Journal of Biological Chemistry 264, 1190-1194.

Surdej P, Riedl A \& Jacobs-Lorena M (1994) Regulation of mRNA stability in development. Annual Reviews of Genetics 28, 263282.

Theil EC (1990) Regulation of ferritin and transferrin receptor mRNAs. Journal of Biological Chemistry 265, 4771-4774.

Theil EC (1994) Iron regulatory elements (IREs): a family of mRNA non-coding sequences. Biochemical Journal 304, 1-11.

Tillman JB, Mote PL, Dhahbi JM, Walford RL \& Spindler SR (1996) Dietary energy restriction in mice negatively regulates hepatic glucose-regulated protein 78 (GRP78) expression at the post-transcriptional level. Journal of Nutrition 126, 416-423.

Tohyama C, Suzuki JS, Hemelrad J, Nishimura N \& Nishimura H (1993) Induction of metallothionein and its localisation in the nucleus of rat hepatocytes after partial hepatectomy. Hepatology 18, 1193-1201.

Vasconcelos MH, Tam S-C, Beattie JH \& Hesketh JE (1996) Evidence for differences in the post-transcriptional regulation of rat metallothionein isoforms. Biochemical Journal 315, 665671.

Veyrune J-L, Campbell GP, Wiseman J, Blanchard J-M \& Hesketh JE (1996) A localisation signal in the $3^{\prime}$ untranslated region of c-myc mRNA targets c-myc mRNA and $\beta$-globin reporter sequences to the perinuclear cytoplasm and cytoskeletal-bound polysomes. Journal of Cell Science 109, 1185-1194.

Veyrune J-L, Carillo S, Vie A \& Blanchard J-M (1995) c-fos mRNA instability determinants present within both the coding and the $3^{\prime}$ non coding region link the degradation of this mRNA to its translation. Oncogene 11, 2127-2134.

Wilson IA, Brindle K \& Fulton AM (1995) Differential localisation of the mRNA of the $\mathrm{M}$ and $\mathrm{B}$ forms of creatine kinase in myoblasts. Biochemical Journal 308, 599-605.

Wolfe SL (1993) Molecular and Cellular Biology. California: Wadsworth Publishing Company.

Yokota T, Kanamoto R \& Hayashi S (1995a) Effects of dietary protein on the induction of DNA synthesis and expression of growth-related genes in liver and kidney of growing rats. Journal of Nutritional Science and Vitaminology 41, 227-239.

Yokota T, Kanamoto R \& Hayashi S (1995b) c-myc mRNA is stabilised by deprivation of amino acids in primary cultured rat hepatocytes. Journal of Nutritional Science and Vitaminology 41, 455-463. 